\title{
New Magnetic Fe Oxide-Carbon Based Acid Catalyst Prepared from Bio-Oil for Esterification Reactions
}

\author{
Fabiane C. Ballotin, ${ }^{a}$ Vitor F. Almeida, ${ }^{a}$ José D. Ardisson, ${ }^{b}$ Márcio J. da Silva, ${ }^{c}$ \\ Ricardo R. Soares, ${ }^{\circledR d}$ Ana Paula C. Teixeira ${ }^{\circledR *}{ }^{* a}$ and Rochel M. Lago ${ }^{a}$ \\ ${ }^{a}$ Departamento de Química, Universidade Federal de Minas Gerais, 31270-901 Belo Horizonte-MG, Brazil \\ ${ }^{b}$ Centro de Desenvolvimento da Tecnologia Nuclear, 31270-901 Belo Horizonte-MG, Brazil \\ 'Departamento de Química, Universidade Federal de Viçosa, 36570-900 Viçosa-MG, Brazil \\ ${ }^{d}$ Faculdade de Engenharia Química, Universidade Federal de Uberlândia, 38408-100 Uberlândia-MG, Brazil
}

\begin{abstract}
In this work, bio-oil (an organic matrix rich in oxygen functionalities) was used to efficiently dissolve and disperse $\mathrm{Fe}^{3+}$ which upon thermal treatment produced a carbon containing dispersed and encapsulated Fe oxide magnetic nanoparticles. These materials were prepared by dissolution of 8,16 and 24 wt. $\% \mathrm{Fe}^{3+}$ salt in bio-oil followed by treatment at $400,450,500$ or $600{ }^{\circ} \mathrm{C}$ in $\mathrm{N}_{2}$ atmosphere. X-ray diffraction (XRD), scanning (SEM) and transmission electron microscopies (TEM), elemental analysis, thermogravimetric-mass spectrometry (TG-MS), potentiometric titration, Raman and Mössbauer spectroscopies showed that $\mathrm{Fe}^{3+}$ species in bio-oil is reduced to produce magnetic nanoparticles phases: magnetite $\mathrm{Fe}_{3} \mathrm{O}_{4}$ and maghemite $\gamma-\mathrm{Fe}_{2} \mathrm{O}_{3}$. At low temperatures, the iron phases were less protected, and the carbon matrix was more reactive, while in temperatures above $500{ }^{\circ} \mathrm{C}$, the iron phases were more stable, however, the carbon matrix was less reactive. Reaction of these magnetic carbon materials with concentrated $\mathrm{H}_{2} \mathrm{SO}_{4}$ produced surface sulfonic acidic sites (ca. $1 \mathrm{mmol} \mathrm{g}^{-1}$ ), especially for the materials obtained at 400 and $450{ }^{\circ} \mathrm{C}$. The materials were used as catalysts on esterification reaction of oleic acid with methanol at $100{ }^{\circ} \mathrm{C}$ and conversions of $90 \%$ were reached, however, after 2 consecutive uses, the conversion decreased to $30 \%$, being required more studies to improve the material stability.
\end{abstract}

Keywords: bio-oil, $\mathrm{Fe}^{3+}$ dissolution, magnetic carbons, sulfonation, acid catalyst, esterification

\section{Introduction}

Bio-oil is a renewable and low-cost feedstock, which is generated by biomass flash pyrolysis. ${ }^{1,2}$ It is composed by water, alcohols, furans, acids, ketones, carbohydrates, ${ }^{3}$ and usually have highly oxygenated large carbon structures., ${ }^{4,5}$ These oxygen groups are considered undesirable since they bring some properties such as acidity, corrosion and thermal instability. ${ }^{6}$ Different upgrade processes such as cracking, ${ }^{7}$ decarboxylation, ${ }^{8}$ decarbonylation, ${ }^{9}$ hydrodeoxygenation ${ }^{10}$ have been investigated to decrease the oxygen content to convert bio-oil into fuel, ${ }^{11}$ adhesives $^{12}$ and chemicals. ${ }^{13}$

On the other hand, very few studies ${ }^{14-16}$ have taken advantage of the oxygen and acidic properties of bio-oil. For example, the acidic characteristics of the aqueous fraction of bio-oil was used to extract iron from mining tailings to

*e-mail: anapct@ufmg.br produce different materials and fuels ${ }^{14}$ and derivatization of esterification reactions. ${ }^{15}$ The reactivity of the oxygen groups of bio-oil have also been used to produce carbon nanostructures such as graphene, nongraphite, nanotubes and nanoparticles by the simple reaction with $\mathrm{H}_{2} \mathrm{SO}_{4} \cdot{ }^{16}$

In this work, bio-oil structural oxygen acidic groups were used to disperse $\mathrm{Fe}^{3+}$ ions. Upon thermal decomposition at different temperatures, $400-600{ }^{\circ} \mathrm{C}$, $\mathrm{Fe}^{3+} /$ bio-oil solution produces a carbon containing $\mathrm{Fe}$ oxides magnetic nanoparticles due to the carbonization and reduction of highly dispersed $\mathrm{Fe}^{3+}$ species. These magnetic carbon materials can have several applications in different areas such as catalysis, ${ }^{17-19}$ adsorption, ${ }^{20}$ drug delivery, ${ }^{21}$ hyperthermic materials. ${ }^{22}$

It is also described the sulfonation of these carbons, which showed reactivity dependent of thermal treatment temperature to produce magnetic acid materials which have potential application in acid-catalyzed reactions. ${ }^{23}$ They can be used in hydrogenation, ${ }^{24}$ photocatalysis, ${ }^{25}$ 
electrocatalysis, ${ }^{26}$ dehydration and dehydrogenation of alcohols ${ }^{27}$ and esterification reactions. ${ }^{28}$

The catalytic esterification of fatty acids was also evaluated using sulfonated carbon based on bio-oil, once this reaction is an important alternative to convert acid vegetable oils into biodiesel. Sulfuric acid has been used as homogeneous catalyst, ${ }^{29}$ however, corrosion problems and loss of the catalyst have been considered important drawbacks. ${ }^{30,31}$

Therefore, the sulfonation process of carbon materials to develop heterogeneous catalysts to produce biodiesel using acidic oils is of considerable importance. ${ }^{32,33}$ Biomass incomplete carbonization and sulfonation has been done to produce acid catalyst. In literature, it was found that corn straw, ${ }^{29}$ glucose ${ }^{30}$ and starch of mung bean, ${ }^{31}$ were used as carbon source to produce sulfonated carbon materials with $2.64,1.0$ and $1.53 \mathrm{~mol} \mathrm{~g}^{-1}$ of acidity which were used as acid catalysts on esterification reactions.

Thus, in this work, a novel application of bio-oil to produce an efficient acidic and magnetic carbon-based catalysts was investigated.

\section{Experimental}

\section{Bio-oil production}

Bio-oil was obtained in a plant at Federal University of Uberlândia, MG, Brazil, from pyrolysis of sugarcane straw at $450{ }^{\circ} \mathrm{C}$. It is composed of carbohydrates, phenols, furans, guaiacols, syringols and presented $46 \% \mathrm{C}$ and $7 \%$ of $\mathrm{H}^{16}$

\section{Iron impregnation}

Bio-oil (5.0138 g) was dissolved in $20 \mathrm{~mL}$ of ethanol and impregnated with an ethanolic solution of 8,16 and 24 wt.\% $\mathrm{Fe}, \mathrm{Fe}\left(\mathrm{NO}_{3}\right)_{3} .9 \mathrm{H}_{2} \mathrm{O} .{ }^{34,35}$ The solution remained under stirring for $30 \mathrm{~min}$. After this time, the solvent was evaporated and the solid obtained were dried for $12 \mathrm{~h}$ at $353 \mathrm{~K}$. The dried sample were named here as $\mathrm{B} 8 \mathrm{Fe}, \mathrm{B} 16 \mathrm{Fe}$ or $\mathrm{B} 24 \mathrm{Fe}$, respective to the $\mathrm{Fe}$ percentage.

\section{Pyrolysis}

About $800 \mathrm{mg}$ of $\mathrm{B} 8 \mathrm{Fe}$ were thermally treated in a tubular oven at $400,450,500$ and $600{ }^{\circ} \mathrm{C}$ for $1 \mathrm{~h}$ in $\mathrm{N}_{2}$ atmosphere $\left.\left(50 \mathrm{~mL} \mathrm{~min}^{-1}\right)\right)^{34,35}$ The obtained materials were named hereon as $(\mathrm{B} 8 \mathrm{Fe})_{400},(\mathrm{~B} 8 \mathrm{Fe})_{450},(\mathrm{~B} 8 \mathrm{Fe})_{500}$ and $(\mathrm{B} 8 \mathrm{Fe})_{600}$, respective to the thermal treatment temperature.

\section{Sulfonation}

$0.5000 \mathrm{mg}$ of the pyrolyzed sample was submitted to a sulfonation reaction with a ratio $9.2: 1 \mathrm{~m} / \mathrm{m}$ of concentrated $\mathrm{H}_{2} \mathrm{SO}_{4}$ :bio-oil at $120^{\circ} \mathrm{C}$ for $2 \mathrm{~h}$, under magnetic stirring. ${ }^{28,36}$ After the reaction, the materials were washed with distilled water until $\mathrm{pH}$ ca. 5.50 and dried at $80{ }^{\circ} \mathrm{C}$ for $12 \mathrm{~h}$. The catalyst yield was calculated according to equation 1 :

$\operatorname{Yield}(\%)=\left(\mathrm{w}_{\text {final }} / \mathrm{w}_{\text {initial }}\right) \times 100$

where $\mathrm{w}_{\text {initial }}$ is the material weight before thermal treatment and $\mathrm{w}_{\text {final }}$ is the weight after pyrolysis and sulfonation process.

The catalysts were named as $(\mathrm{B} 8 \mathrm{Fe})_{400} \mathrm{~S}$, where $\mathrm{S}$ refers to sulfuric acid treatment.

\section{Materials characterization}

The content of some elements (carbon, hydrogen, nitrogen and sulfur) on the synthesized materials was determined by elemental analysis using PerkinElmer CHN analyzer. Scanning electron microscopy (SEM) images were obtained in a FIB, Quanta FEG 3D FEI equipment. The samples were dispersed in acetone and deposited onto a silicon plate. The transmission electron microscopy (TEM) images were obtained in a G2-20, SuperTwin FEI, $200 \mathrm{kV}$.

$\mathrm{X}$-ray diffraction (XRD) studies were performed on a Shimadzu diffractometer, model XRD-7000 with $\mathrm{Cu} \mathrm{K} \alpha$ and a scan speed of $4^{\circ} \mathrm{min}^{-1}$. Thermogravimetric analysis (TGA) was performed on a Shimadzu DTG 60H with air flow $\left(50 \mathrm{~mL} \mathrm{~min}^{-1}\right)$ and a heating rate of $10 \mathrm{~K} \mathrm{~min}^{-1}$ up to 1273 K. Catalyst acidity was measured by potentiometric titration. The solid $(0.05 \mathrm{~g})$ were suspended in acetonitrile $(40 \mathrm{~mL})$ and shaken for $24 \mathrm{~h}$. Then, the suspension was potentiometrically titrated with a $0.025 \mathrm{~mol} \mathrm{~L}^{-1}$ $n$-butylamine solution in toluene. The electrode potential variation was measured with a BEL $\mathrm{pH}$ instrument.

Simultaneous thermogravimetric-mass spectrometry (TG-MS) analyses were performed. The base peaks $(\mathrm{m} / \mathrm{z}, 18,28,44,64$ and 80$)$ were selected to be monitored in a NETZSCH TG/STA equipment coupled with Aelos spectrometer, model 7.0. The samples specific surface areas were analyzed by adsorption of $\mathrm{N}_{2}$ at $77 \mathrm{~K}$ using analyzer Quantachrome, model NOVA 1200e. The samples were degassed at $80^{\circ} \mathrm{C}$ for $4 \mathrm{~h}$ before the analyses. The absorption spectroscopy measurements in the infrared region with Fourier transform (FTIR) attenuated total reflectance (ATR) were performed on PerkinElmer equipment, model Spectrum 1000. Spectra were collected in the range of $400-4000 \mathrm{~cm}^{-1}$ region, with 64 accumulations. 
Raman spectra of carbon material obtained from bio-oil were acquired using Raman Senterra spectrometer, $532 \mathrm{~nm}$ laser line was used for excitation with the exposure time of $60 \mathrm{~s}$ and $10 \mathrm{~mW}$ of power.

${ }^{57} \mathrm{Fe}$ Mössbauer spectra (MS) were obtained at room temperature and at $30 \mathrm{~K}$, in transmission geometry with a source of ${ }^{57} \mathrm{Co}$ in $\mathrm{Rh}$ matrix. Spectral hyperfine parameters were calculated using the Normos least-squares-fit software package. $^{32}$

\section{Catalytic runs}

The esterification reactions of oleic acid with methanol were performed in a sealed tube glass reactor with sampling septum in a thermostatic bath with magnetic stirring. Dodecane was used as internal standard. The solid catalysts, i.e., $(\mathrm{B} 8 \mathrm{Fe})_{400} \mathrm{~S},(\mathrm{~B} 8 \mathrm{Fe})_{450} \mathrm{~S},(\mathrm{~B} 8 \mathrm{Fe})_{500} \mathrm{~S}$ and $(\mathrm{B} 8 \mathrm{Fe})_{600} \mathrm{~S}$, were used in variable loads (ca. 1-10 wt.\%). The reactions were performed at temperature ranging of $60-100{ }^{\circ} \mathrm{C} .{ }^{37} \mathrm{The}$ oleic acid:methanol molar ratio used was $1: 30^{38}(0.58 \mathrm{~mL}$ of oleic acid and $2.22 \mathrm{~mL}$ of methanol).

\section{Catalyst reuse}

The reuse test was performed using $10 \mathrm{wt} . \%$ of catalyst $(\mathrm{B} 8 \mathrm{Fe})_{450} \mathrm{~S}, 1: 30$ oleic acid:methanol, at $100{ }^{\circ} \mathrm{C}$ during $6 \mathrm{~h}$. After each reaction, the catalyst was separated from the products using a magnet, washed with methanol and reuse reactions were performed.

\section{Catalyst leaching}

Leaching was evaluated at the oleic acid:methanol molar ratio of 1:30, using $10 \mathrm{wt} . \%$ of catalyst $(\mathrm{B} 8 \mathrm{Fe})_{450} \mathrm{~S}$. For the tests, the catalyst was transferred to the reaction medium containing only methanol. The system was maintained under constant stirring for $90 \mathrm{~min}$ at $100{ }^{\circ} \mathrm{C}$. After this period, methanol was removed and transferred to a vial containing only oleic acid, thus proceeding with the reaction.

\section{Analysis of products}

After the reaction, the mixture was dissolved in $3 \mathrm{~mL}$ of hexane. The methyl ester was quantified in a gas chromatography coupled with flame ionization detector (GC-FID) using a Shimadzu GC-2010, equipped with a Carbowax capillary column $(0.25 \mathrm{~m} \times 0.25 \mathrm{~mm} \times 30 \mathrm{~m})$.

\section{Results and Discussion}

Previous GC-MS and ${ }^{1} \mathrm{H}$ nuclear magnetic resonance
(NMR) characterization of bio-oil showed a complex matrix composed of syringols, phenols, carboxylic acids, aldehydes, ketones, alcohols and a heavier fraction containing oligomers with different oxygen functionalities. ${ }^{16}$ FTIR and elemental analyses confirmed the presence of a great amount of oxygen groups, ca. 48\% (Figure 1).

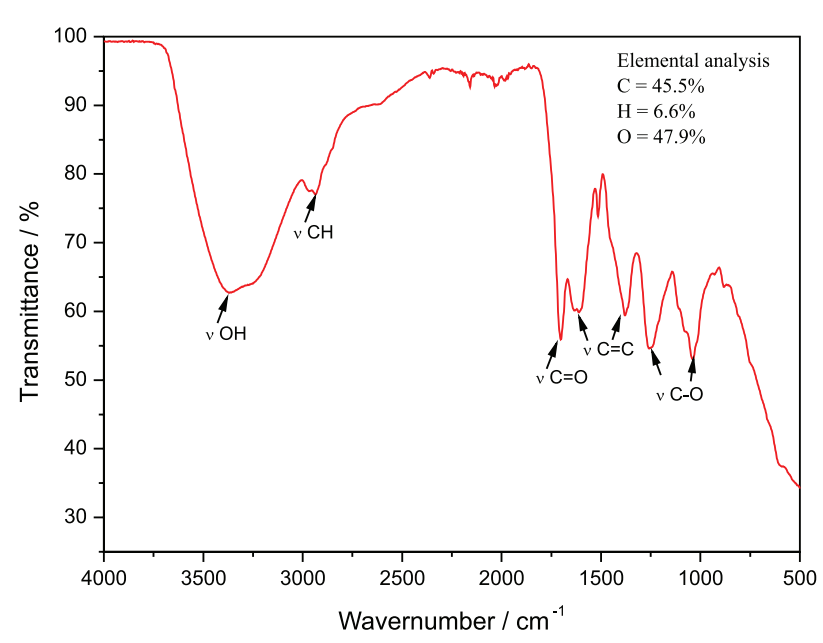

Figure 1. Infrared spectrum (ATR) and elemental analysis of bio-oil (adapted from reference 16).

It is interesting to observe that $\mathrm{Fe}\left(\mathrm{NO}_{3}\right)_{3}$ could be well solubilized in rather hydrophobic organic matrix bio-oil. Although the mechanism responsible for this solubilization of $\mathrm{Fe}^{3+}$ is not clear, the interaction/complexation with different oxygen groups such as phenolic and carboxylic is most likely involved in this process.

Three different bio-oil solutions in ethanol were prepared containing 8,16 and $24 \mathrm{wt} . \% \mathrm{Fe}\left(\mathrm{NO}_{3}\right)_{3}$ (in relation to bio-oil content). After $30 \mathrm{~min}$ of stirring, the solvent was evaporated to produce a viscous/vitreous precursor. No visual indication that $\mathrm{Fe}\left(\mathrm{NO}_{3}\right)_{3}$ was crystallized, segregated or separated from the bio-oil was observed. The precursors were thermally treated in nitrogen atmosphere at $450{ }^{\circ} \mathrm{C}$ for $1 \mathrm{~h}$.

XRD analyses of the obtained materials (Figure S1, Supplementary Information (SI) section) showed the formation of magnetic iron phases, e.g., magnetite $\left(\mathrm{Fe}_{3} \mathrm{O}_{4}\right) /$ maghemite $\left(\gamma-\mathrm{Fe}_{3} \mathrm{O}_{4}\right)$. The samples were sulfonated with $\mathrm{H}_{2} \mathrm{SO}_{4}$ and tested as catalysts in oleic acid esterification reactions. The tests showed that when materials $(\mathrm{B} 16 \mathrm{Fe})_{450} \mathrm{~S}$ and $(\mathrm{B} 24 \mathrm{Fe})_{450} \mathrm{~S}$ were used, a large amount of iron oxide was leached, and no formation of biodiesel occurred. Probably, in these samples, the carbon was not sufficient to protect the iron phases.

Therefore, the effect of thermal treatment was investigated in more detail for the sample B8Fe which was treated at $400,450,500$ and $600{ }^{\circ} \mathrm{C}$. In general, the samples presented low cristallinity as showed by XRD (Figure S2, 
SI section), with two peaks observed for all samples at ca. $24^{\circ}$ related to the amorphous carbon ${ }^{33}$ and $35^{\circ}$, likely related to $\mathrm{Fe}_{3} \mathrm{O}_{4}$ (magnetite) (JCPDS1-1111) or $\gamma-\mathrm{Fe}_{2} \mathrm{O}_{3}$ (maghemite) (JCPDS:39-1346). ${ }^{39}$

After sulfonation (Figure 2), a broad peak at $24^{\circ}$ was observed for sample (B8Fe) ${ }_{400} \mathrm{~S}$. However, the peak related to iron phase disappeared, due to iron leaching in the presence of $\mathrm{H}_{2} \mathrm{SO}_{4}$.

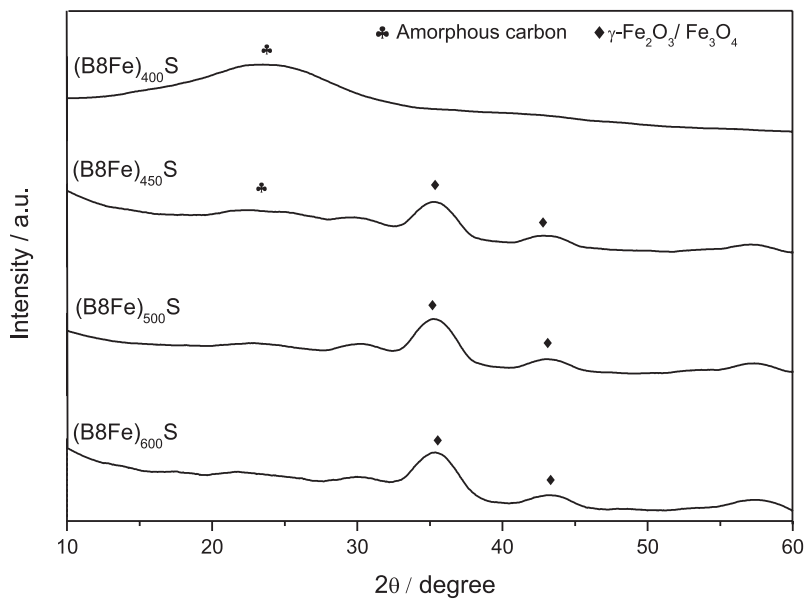

Figure 2. XRD patterns of samples $(\mathrm{B} 8 \mathrm{Fe})_{400} \mathrm{~S},(\mathrm{~B} 8 \mathrm{Fe})_{450} \mathrm{~S},(\mathrm{~B} 8 \mathrm{Fe})_{500} \mathrm{~S}$ and $(\mathrm{B} 8 \mathrm{Fe})_{600} \mathrm{~S}$.

As the temperature of treatment increased, the iron phase became more structured and the peaks at 35 and $43^{\circ}$ related to $\mathrm{Fe}_{3} \mathrm{O}_{4}$ (magnetite) or $\gamma-\mathrm{Fe}_{2} \mathrm{O}_{3}$ (maghemite) were observed. Scherrer equation was used to estimate the crystallite size of the iron oxide which was in the range of 3-5 nm.

Mössbauer spectra before (Figure S3, SI section) and after sulfonation (Figure 3), consisted of a set of six-lines pattern related to a ferromagnetic material indicating a mixture of maghemite/magnetite (hyperfine parameters are shown in Table S1, SI section). According to measurements, the samples at room temperature presented a superparamagnetic behavior. At $30 \mathrm{~K},(\mathrm{~B} 8 \mathrm{Fe})_{450}$ and $(\mathrm{B} 8 \mathrm{Fe})_{450} \mathrm{~S}$ still present superparamagnetic character, however, as temperature of thermal treatment increased, the samples presented a higher degree of organization.

According to XRD and Mössbauer results, after biooil impregnation with $\mathrm{Fe}\left(\mathrm{NO}_{3}\right)_{3}$ and thermal treatment (400-600 ${ }^{\circ} \mathrm{C}$ ) under $\mathrm{N}_{2}$ atmosphere, occurred the partial reduction of $\mathrm{Fe}^{3+}$ leading to the formation of a $\mathrm{Fe}^{2+} / \mathrm{Fe}^{3+}$ oxide. Although the mechanism for this reduction is not clear, it is most likely that reducing species such as $\mathrm{H}_{2}$, $\mathrm{CO}$, organics and amorphous carbon formed during bio-oil decomposition ${ }^{40}$ are involved in $\mathrm{Fe}^{3+}$ reduction.

SEM analyses of material treated at $400{ }^{\circ} \mathrm{C}$ (Figure 4) showed that before sulfonation, the material presented particles between 50 and $300 \mu \mathrm{m}$. Moreover, mapping and

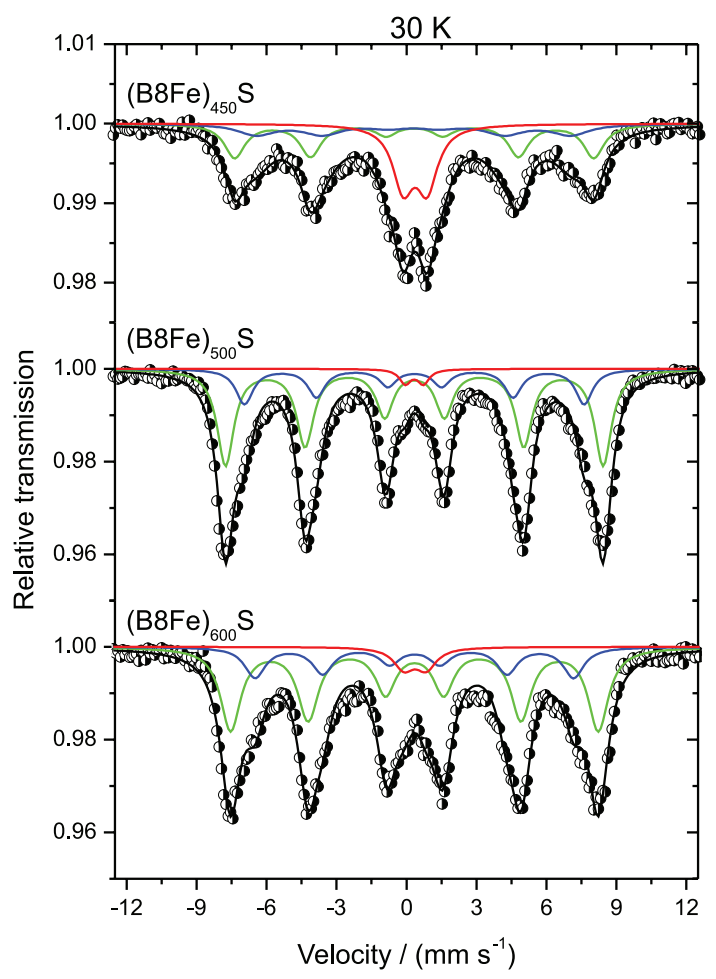

Figure 3. Mössbauer spectra at $30 \mathrm{~K}$ of samples $(\mathrm{B} 8 \mathrm{Fe})_{450} \mathrm{~S}$, $(\mathrm{B} 8 \mathrm{Fe})_{500} \mathrm{~S}$ and $(\mathrm{B} 8 \mathrm{Fe})_{600} \mathrm{~S}$.

energy-dispersive X-ray spectroscopy (EDS) (Figure S4, SI section) analyses showed that iron was leached by sulfuric acid indicating that the carbon formed did not encapsulate/ protect the Fe oxide particles.

After sulfonation (Figure 4), particles of $50 \mu \mathrm{m}$ and irregular surfaces were observed.

TEM images for material treated at $400{ }^{\circ} \mathrm{C}$ and sulfonated showed no iron in its structure confirming acid leaching (Figure S5, SI section). For samples treated at temperatures 450,500 and $600{ }^{\circ} \mathrm{C}$ (Figures 5-6), iron was dispersed all over the materials surface and remained encapsulated by the carbon matrix. The images and histogram (Figure 6) showed that iron nanoparticles have sizes between $5-20 \mathrm{~nm}$.

The yield of catalyst synthesis as well as the evaluation of the sulfonation process was carried out by elemental analyses. Table 1 shows $\mathrm{C}, \mathrm{H}, \mathrm{N}$ and $\mathrm{S}$ contents in these materials.

After pyrolysis and $\mathrm{H}_{2} \mathrm{SO}_{4}$ reaction, the materials were ground and extensively washed with deionized water until $\mathrm{pH}$ 6.0. In general, the materials yield decreased with pyrolysis temperature increase: 50.3, 47.3, 42.1 and $39.7 \%$ for $(\mathrm{B} 8 \mathrm{Fe})_{400} \mathrm{~S},(\mathrm{~B} 8 \mathrm{Fe})_{450} \mathrm{~S},(\mathrm{~B} 8 \mathrm{Fe})_{500} \mathrm{~S}$ and $(\mathrm{B} 8 \mathrm{Fe})_{600} \mathrm{~S}$, respectively. Indeed, at higher temperatures more volatiles were released from the organic matrix.

The original bio-oil (before thermal treatment and sulfonation) presented $45.5,6.6$ and $0.5 \%$ of $\mathrm{C}, \mathrm{H}$ and 


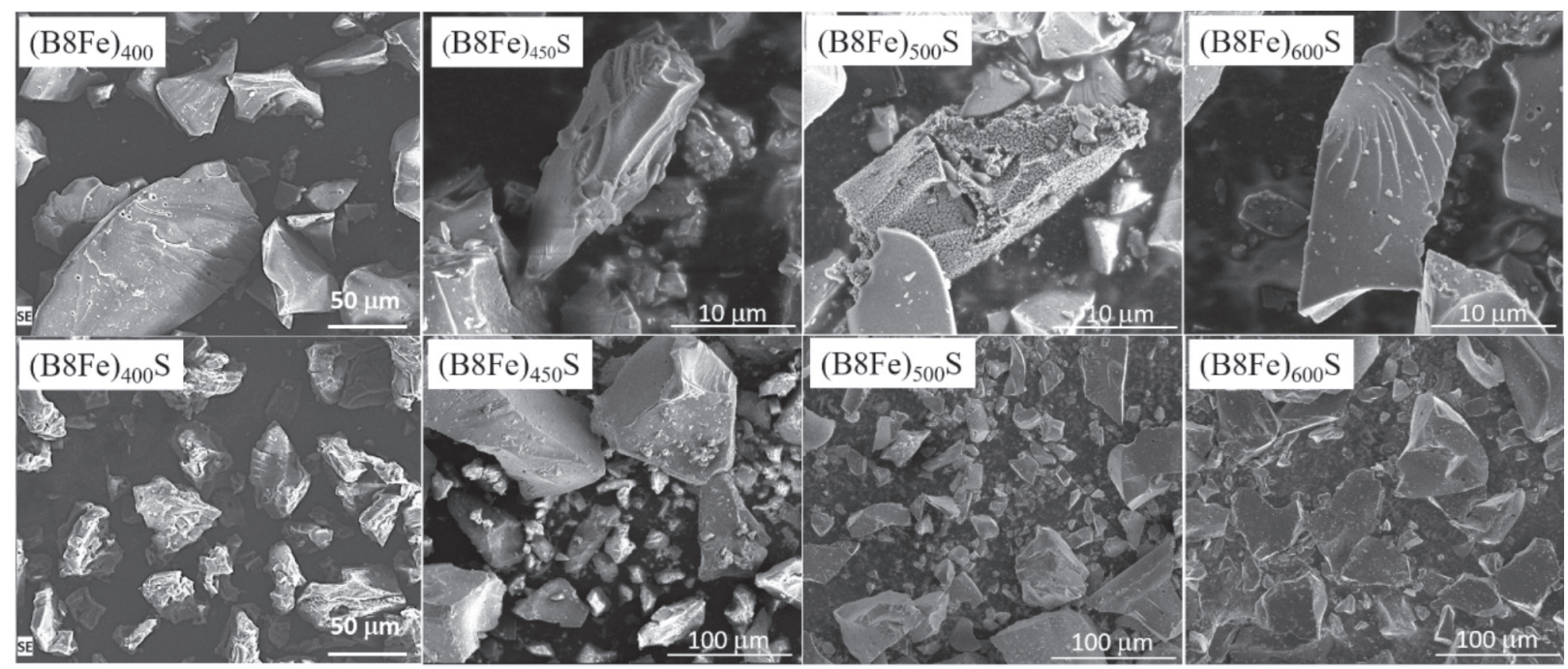

Figure 4. Scanning electron microscopy images of iron materials before, $(\mathrm{B} 8 \mathrm{Fe})_{400}$, and after sulfonation $(\mathrm{B} 8 \mathrm{Fe})_{400} \mathrm{~S},(\mathrm{~B} 8 \mathrm{Fe})_{450} \mathrm{~S},(\mathrm{~B} 8 \mathrm{Fe})_{500} \mathrm{~S}$ and $(\mathrm{B} 8 \mathrm{Fe})_{600} \mathrm{~S}$.

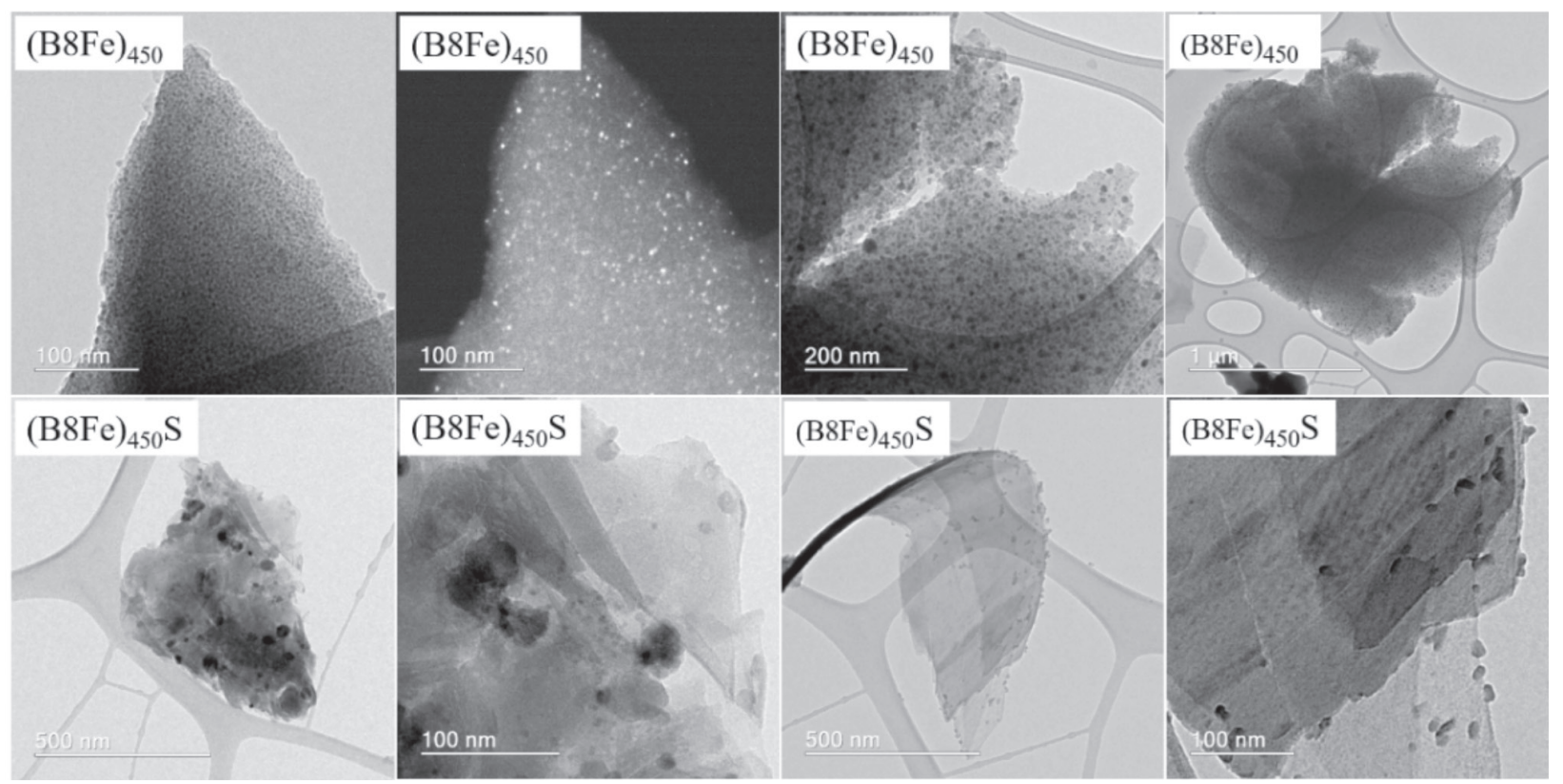

Figure 5. Transmission electron microscopy images of materials $(\mathrm{B} 8 \mathrm{Fe})_{450}$ and $(\mathrm{B} 8 \mathrm{Fe})_{450} \mathrm{~S}$.

$\mathrm{N},{ }^{16}$ respectively. According to elemental analysis, carbon content increased from ca. 46 to $48-54 \%$ and the $\mathrm{H}$ content decreased for sample (B8Fe) ${ }_{400} \mathrm{~S}$, due to dehydration and carbonization. Furthermore, the presence of $3.4-4.5 \% \mathrm{~N}$ indicates the presence of non-decomposed nitrate and likely nitrogen groups formed during the process.

Relatively high sulfur content was observed, i.e., $5.0 \%$, for the sample $(\mathrm{B} 8 \mathrm{Fe})_{400} \mathrm{~S}$ likely due to the sulfonation of the carbon formed after treatment at $400{ }^{\circ} \mathrm{C}$. On the other hand, $\mathrm{S}$ decreased to $3.8,2.5$ and $2.2 \%$ as the material was pre-treated at 450,500 and $600{ }^{\circ} \mathrm{C}$, respectively. This result suggests that thermal treatment at temperatures higher than $400{ }^{\circ} \mathrm{C}$ is producing carbons that are well structured and more difficult to sulfonate.
Raman spectra of materials (Figure 7) showed two bands characteristics of carbonaceous materials ${ }^{41}$ the $\mathrm{G}$ band $\left(1590 \mathrm{~cm}^{-1}\right)$, which is related to more organized graphitic structures, and D band $\left(1350 \mathrm{~cm}^{-1}\right)$, which indicates the presence of defects in carbonaceous structures and amorphous carbon.

The $D$ band intensity to $G$ band ratio $\left(I_{D} / I_{G}\right)$ is high (approximately 0.9) for all the materials spectra, which were also verified on other studies. ${ }^{41}$ These results can be indicated that the materials have high degree of defects.

The FTIR spectra of sulfonated materials (Figure S6, SI section) showed two bands at 1583 and $1688 \mathrm{~cm}^{-1}$ related to aromatic $\mathrm{C}=\mathrm{C}$ bonds ${ }^{42}$ Furthermore, for material $(\mathrm{B} 8 \mathrm{Fe})_{400} \mathrm{~S}$ a broad band near $3026 \mathrm{~cm}^{-1}$ related to $-\mathrm{OH}$ 

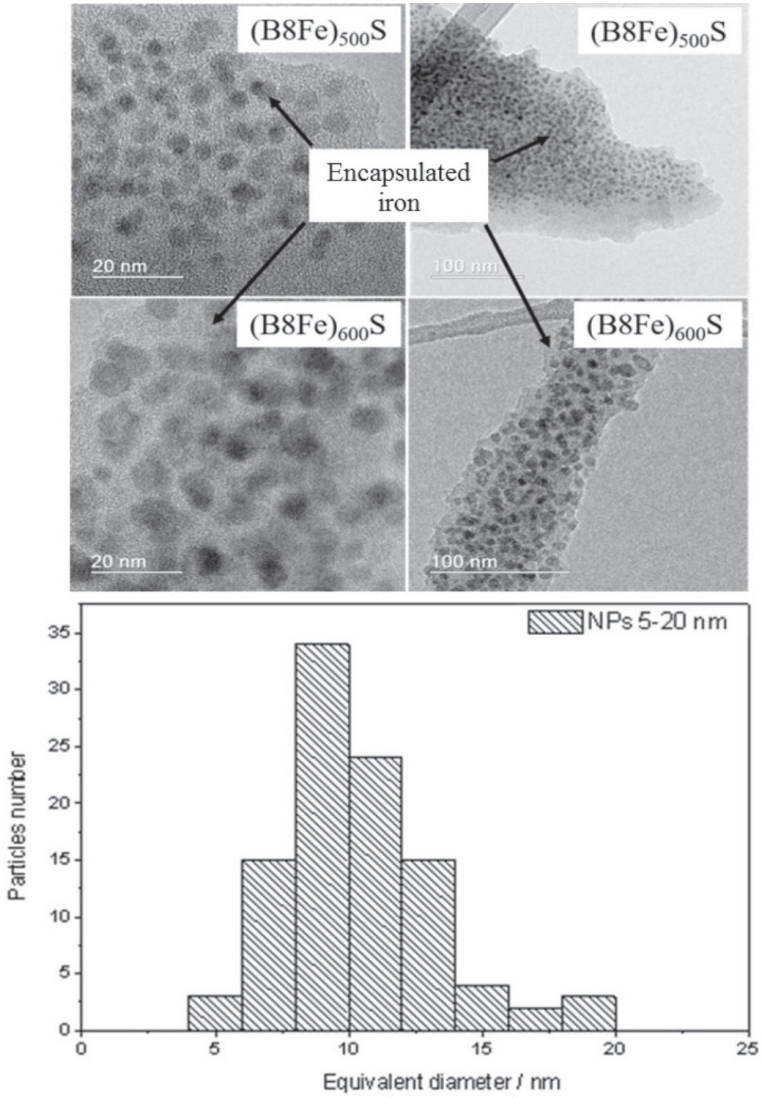

Figure 6. (Top) Transmission electron microscopy images of materials $(\mathrm{B} 8 \mathrm{Fe})_{500} \mathrm{~S}$ and $(\mathrm{B} 8 \mathrm{Fe})_{600} \mathrm{~S}$ and (bottom) particle size distribution.

Table 1. $\mathrm{C}, \mathrm{H}$ and $\mathrm{N}$ content of bio-oil and materials impregnated with $8 \mathrm{wt} . \%$ of iron $(\mathrm{B} 8 \mathrm{Fe})$ and sulfonated

\begin{tabular}{lcccc}
\hline Sample & $\mathrm{C} / \%$ & $\mathrm{H} / \%$ & $\mathrm{~N} / \%$ & $\mathrm{~S} / \%$ \\
\hline Bio-oil & 45.5 & 6.6 & 0.5 & - \\
$(\mathrm{B} 8 \mathrm{Fe})_{400} \mathrm{~S}$ & 54.3 & 2.9 & 4.4 & 5.0 \\
$(\mathrm{~B} 8 \mathrm{Fe})_{450} \mathrm{~S}$ & 49.0 & 3.1 & 4.5 & 3.8 \\
$(\mathrm{~B} 8 \mathrm{Fe})_{500} \mathrm{~S}$ & 50.3 & 2.5 & 4.1 & 2.5 \\
$(\mathrm{~B} 8 \mathrm{Fe})_{600} \mathrm{~S}$ & 48.4 & 1.8 & 3.4 & 2.2 \\
\hline
\end{tabular}

$(\mathrm{B} 8 \mathrm{Fe})_{400} \mathrm{~S},(\mathrm{~B} 8 \mathrm{Fe})_{450} \mathrm{~S},(\mathrm{~B} 8 \mathrm{Fe})_{500} \mathrm{~S},(\mathrm{~B} 8 \mathrm{Fe})_{600} \mathrm{~S}$ : bio-oil impregnated with $8 \mathrm{wt} . \%$ of iron, sulfonated and thermally treated at $400,450,500$ or $600{ }^{\circ} \mathrm{C}$, respectively.

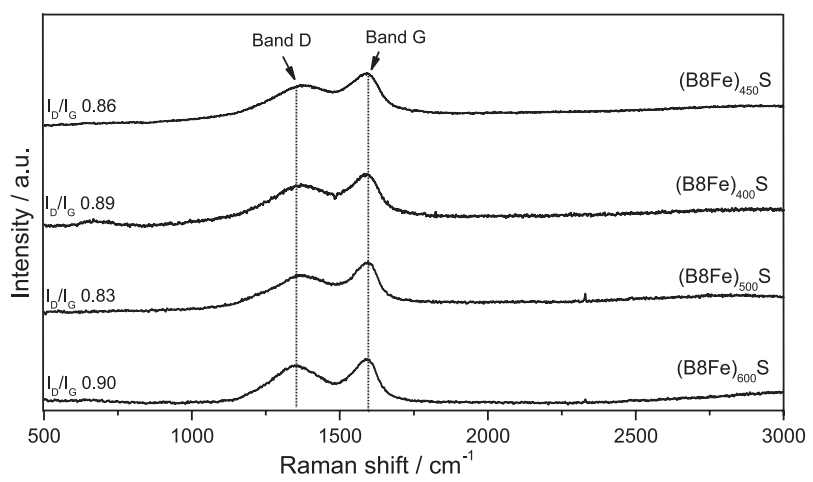

Figure 7. Raman spectra of materials $(\mathrm{B} 8 \mathrm{Fe})_{400} \mathrm{~S},(\mathrm{~B} 8 \mathrm{Fe})_{450} \mathrm{~S},(\mathrm{~B} 8 \mathrm{Fe})_{500} \mathrm{~S}$ and $(\mathrm{B} 8 \mathrm{Fe})_{600} \mathrm{~S}$. stretching was observed. At 1143 and $1019 \mathrm{~cm}^{-1}$, two bands related to the symmetric and asymmetric stretching of $\mathrm{O}=\mathrm{S}=\mathrm{O}$ group indicate the presence of $-\mathrm{SO}_{3} \mathrm{H}$ groups. ${ }^{43}$ At temperatures higher than $400{ }^{\circ} \mathrm{C}$, a significant decrease on the bands intensity was observed, confirming the release of oxygenated compounds during carbonization. ${ }^{44}$ Besides that, decrease on the intensity bands relative to sulfonic groups was also verified. ${ }^{44}$

The TG curves in air of the sample $(\mathrm{B} 8 \mathrm{Fe})_{400}$ showed an initial weight loss of $6 \%$ related to water, followed by $55 \%$ loss between $230-400{ }^{\circ} \mathrm{C}$ related to carbon oxidation/ organics decomposition (Figure S7, SI section) leaving ca. $38 \%$ of iron oxide. On the other hand, the TG curve of the material $(\mathrm{B} 8 \mathrm{Fe})_{400} \mathrm{~S}$ indicated a final iron oxide content of only $7 \%$ due to leaching caused by sulfuric acid treatment.

The materials $(\mathrm{B} 8 \mathrm{Fe})_{500},(\mathrm{~B} 8 \mathrm{Fe})_{500} \mathrm{~S},(\mathrm{~B} 8 \mathrm{Fe})_{600}$ and $(\mathrm{B} 8 \mathrm{Fe})_{600} \mathrm{~S}$ showed similar TG curves (Figure S8, SI section), i.e., mass losses between 300 and $430{ }^{\circ} \mathrm{C}$, concerning the oxidation of carbonaceous structures. In all curves, about 37 to $44 \%$ of the inorganic was observed, before and after the sulfonation process. It is probably related to iron phases which are protected and covered by coal and to ashes from the coal oxidation. ${ }^{45}$ For materials $(\mathrm{B} 8 \mathrm{Fe})_{450}$ and $(\mathrm{B} 8 \mathrm{Fe})_{450} \mathrm{~S}$, the weight loss began near $260^{\circ} \mathrm{C}$, indicating that materials are less stable, leading to a final weight of 30 and $25 \%$, respectively. The higher weight loss for $(\mathrm{B} 8 \mathrm{Fe})_{450} \mathrm{~S}$ could be related to iron leaching.

In order to analyze what occurred during material thermal decomposition, a TG-MS experiment (Figure 8) was performed monitoring the $\mathrm{m} / \mathrm{z}$ signals $18,28,44$ and 64 with materials $(\mathrm{B} 8 \mathrm{Fe})_{450}$ and $(\mathrm{B} 8 \mathrm{Fe})_{450} \mathrm{~S}$, in argon atmosphere. Both samples showed initial weight loss until $150{ }^{\circ} \mathrm{C}$ due to water $(\mathrm{m} / \mathrm{z}, 18)$. Adsorbed $\mathrm{CO}_{2}$ was also released at ca. $100{ }^{\circ} \mathrm{C}$. After 150 up to ca. $700{ }^{\circ} \mathrm{C}$ several signals related to $\mathrm{CO}_{2}$ were observed probably due to the decomposition of oxygen groups present in the carbon structure. The $\mathrm{m} / \mathrm{z}$ signal 28 related to $\mathrm{CO}$ was observed between $600-700{ }^{\circ} \mathrm{C}$ and is usually related to the decomposition of oxygen directly linked to the carbon structures. ${ }^{46}$

It was observed that sulfonation with $\mathrm{H}_{2} \mathrm{SO}_{4}$ caused slight changes in the TG-MS desorption profiles. However, the main difference is the presence of an $\mathrm{m} / \mathrm{z}$ signal 64 between $250-400{ }^{\circ} \mathrm{C}$ related to $\mathrm{SO}_{2}$ originated from $\mathrm{HSO}_{3}{ }^{-}$ surface groups. ${ }^{47}$

The number of acid sites determined based on the total amount of sulfur indicated values of $1.56 \mathrm{mmol} \mathrm{g}^{-1}$ for the sample (B8Fe) ${ }_{400} \mathrm{~S}$ and $1.19 \mathrm{mmol} \mathrm{g}^{-1}$ for $(\mathrm{B} 8 \mathrm{Fe})_{450} \mathrm{~S}$. On the other hand, potentiometric titration measurements (Figure S9, SI section) suggested much lower values of 

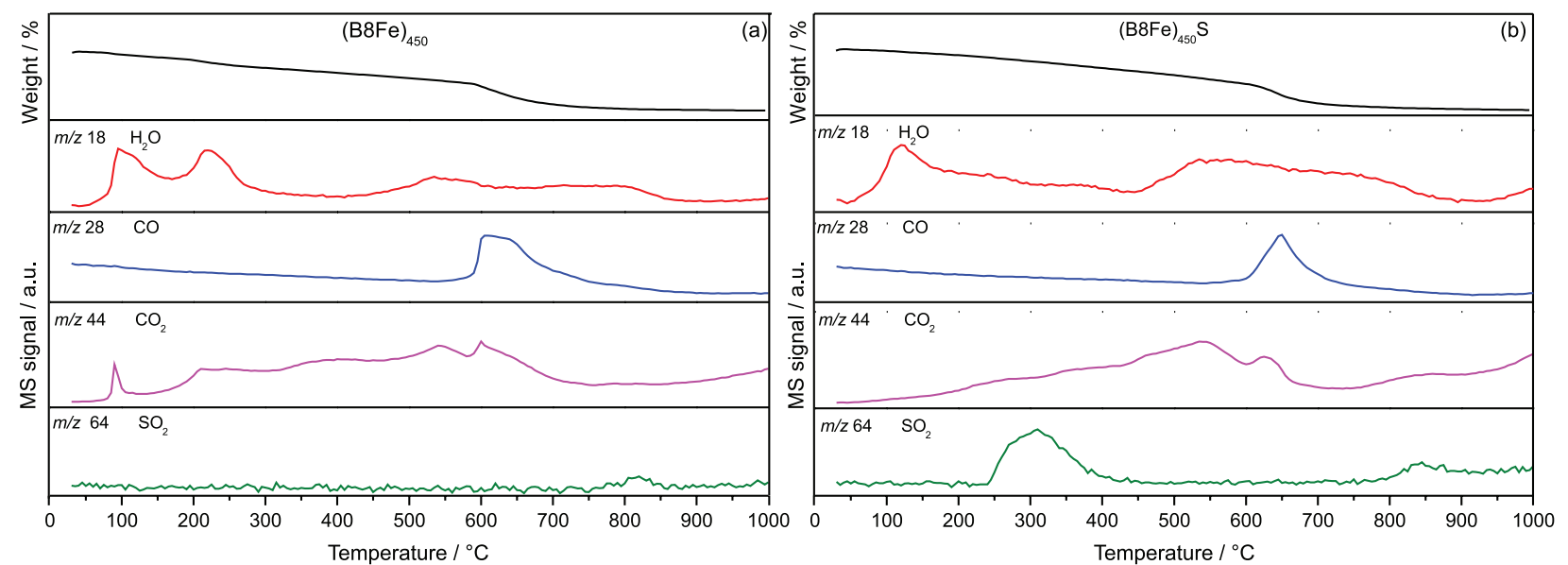

Figure 8. TG and MS curves on argon atmosphere, heating rate of $10^{\circ} \mathrm{C} \mathrm{min}^{-1}$ of materials: (a) $(\mathrm{B} 8 \mathrm{Fe})_{450}$; (b) $(\mathrm{B} 8 \mathrm{Fe})_{450} \mathrm{~S}$.

ca. $0.2 \mathrm{mmol} \mathrm{g}^{-1}$ for the sample (B8Fe) ${ }_{400} \mathrm{~S}$ which strongly decreased for treatment at higher temperatures. Again, these results indicate that thermal treatments at 500 and $600{ }^{\circ} \mathrm{C}$ led to the formation of a very stable carbon less susceptible to sulfonation.

Sulfonated biochar based on pine and starch presented $0.2-0.9 \mathrm{mmol} \mathrm{g}^{-1}$ of acid sites density. ${ }^{48}$ However, solid catalysts based on glucose, ${ }^{49}$ starch and cellulose ${ }^{50}$ presented density of acid sites higher than $1 \mathrm{mmol} \mathrm{g}^{-1}$, which is explained by their large area, pore volume and pore size. According to studies, ${ }^{50}$ materials with larger areas and pore size make the reactants more accessible to $\mathrm{SO}_{3} \mathrm{H}$ groups. Studies ${ }^{46,49}$ showed that lower acid densities can be attributed to higher cross linking and degree of polymerization at higher temperatures, reducing sulfonation efficiency.

The materials were characterized by adsorption/ desorption using Brunauer-Emmett-Teller (BET) method and the surface areas were similar, e.g., 3, 2, 2 and $3 \mathrm{~m}^{2} \mathrm{~g}^{-1}$ for $(\mathrm{B} 8 \mathrm{Fe})_{400} \mathrm{~S},(\mathrm{~B} 8 \mathrm{Fe})_{450} \mathrm{~S},(\mathrm{~B} 8 \mathrm{Fe})_{500} \mathrm{~S}$ and $(\mathrm{B} 8 \mathrm{Fe})_{600} \mathrm{~S}$, respectively. These low values can be attributed to the presence of a great amount of organic compounds, which could be released at higher temperatures. ${ }^{51-53}$

\section{Catalytic tests}

Esterification reactions of oleic acid in the presence of methanol catalyzed by the produced materials were studied (Figure 9). The use of the same quantity of catalyst, e.g., 10 wt. $\%, 1: 30$ oleic acid:methanol, for $6 \mathrm{~h}$ at $100{ }^{\circ} \mathrm{C}$, showed different conversions. As expected, when the material ( $\mathrm{B} 8 \mathrm{Fe})_{400} \mathrm{~S}$ was used, the reaction occurred rapidly, reaching the equilibrium in $2 \mathrm{~h}$. The conversion after $6 \mathrm{~h}$ was $99 \%$. In the other hand, when the material $(\mathrm{B} 8 \mathrm{Fe})_{450} \mathrm{~S}$ was used, the reaction gradually reached the equilibrium after $5 \mathrm{~h}$, with a conversion of $90 \% .{ }^{54}$ When other materials were assessed, $(\mathrm{B} 8 \mathrm{Fe})_{500} \mathrm{~S}$ and $(\mathrm{B} 8 \mathrm{Fe})_{600} \mathrm{~S}$, no significant catalytic effect was observed, what corroborates potentiometric titration analysis. The insignificant conversion was also observed for blank reaction and for material $(\mathrm{B} 8 \mathrm{Fe})_{450}$ (not showed).

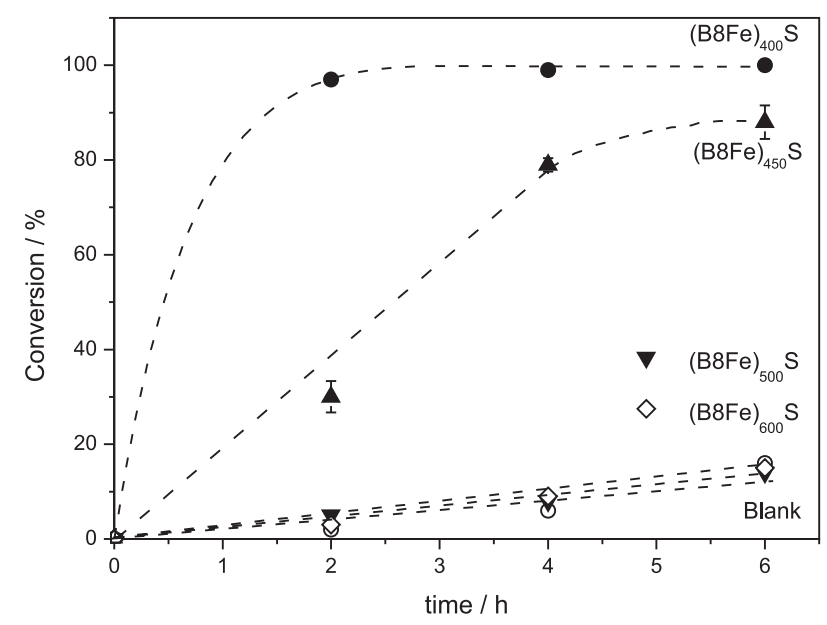

Figure 9. Oleic acid conversion versus time on esterification reaction: effect of the catalyst nature. Reaction conditions: $10 \mathrm{wt} . \%$ catalyst, 1:30 oleic acid:methanol, $100{ }^{\circ} \mathrm{C}$.

The difference on materials catalytic activity is strictly related to pyrolysis temperature. At low temperatures $\left(400-450{ }^{\circ} \mathrm{C}\right)$, the materials were partially carbonized, which allowed the organic groups to react with $\mathrm{H}_{2} \mathrm{SO}_{4}$. The rise of temperature produced a well-structured carbon which present low concentration of surface acid sites, ${ }^{48}$ what was confirmed by CHNS and potentiometric titration. It is also important to highlight that iron played no significant role on the material acidity, once the material $(\mathrm{B} 8 \mathrm{Fe})_{450}$ showed no catalytic activity.

In fact, esterification reactions using wood-based activate carbon catalyst in similar conditions (1:10 oleic acid methanol, $10 \mathrm{wt} . \%$ at $100^{\circ} \mathrm{C}, 3 \mathrm{~h}$ ) had also a significant 
esterification activity, being the biochars synthesized at lower temperatures the most active catalysts. ${ }^{48}$ The more drastic conditions used in this work can be explained due to lower acid sites. In fact, herein, the materials were sulfonated for $2 \mathrm{~h}$ at $120{ }^{\circ} \mathrm{C}$, while in the previous study, ${ }^{48}$ the materials were in contact with $\mathrm{H}_{2} \mathrm{SO}_{4}$ for 12-18 h.

More detailed investigation was carried out with the magnetic catalyst $(\mathrm{B} 8 \mathrm{Fe})_{450} \mathrm{~S}$, in which the temperature effect was studied. The temperature rises from 60 to $100^{\circ} \mathrm{C}$ produced a gradual increase in the yield of esters from 56 to $90 \%$ (Figure 10). This effect is likely kinetic but also related to the higher solubility of methanol in oleic acid, ${ }^{55}$ a high temperature often obtains satisfactory yields, as showed in a study ${ }^{56}$ with acid magnetic catalyst, in which the yield increased from 78.9 to $98.9 \%$ when the temperature rose from 50 to $70{ }^{\circ} \mathrm{C}$.

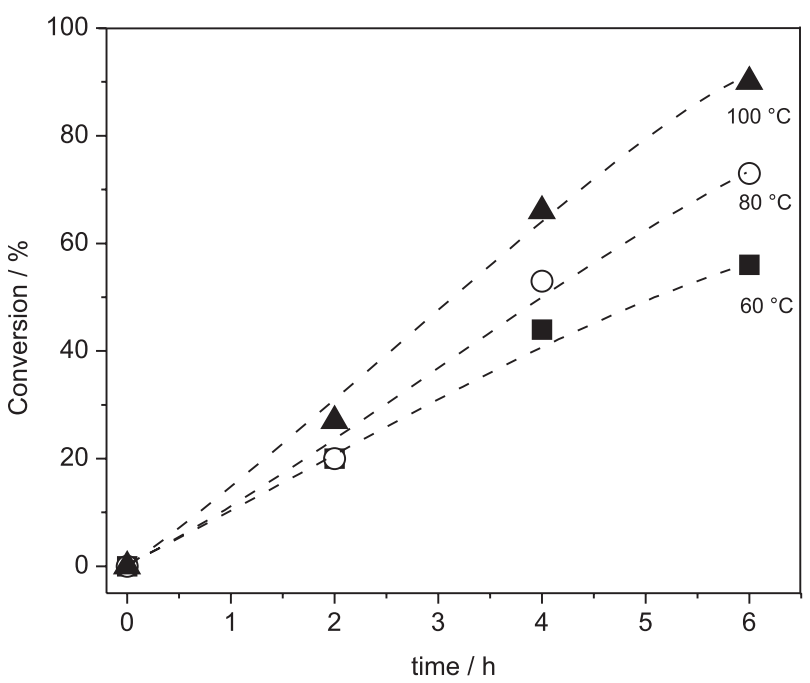

Figure 10. Oleic acid conversion versus time on esterification reaction: effect of the reaction temperature. Reaction conditions: $10 \%$ catalyst $(\mathrm{B} 8 \mathrm{Fe})_{450} \mathrm{~S}, 1: 30$ oleic acid:methanol, $6 \mathrm{~h}$ reaction, at 60,80 and $100{ }^{\circ} \mathrm{C}$.

After the reaction, the catalyst $(\mathrm{B} 8 \mathrm{Fe})_{450} \mathrm{~S}$ was separated from the products using a magnet, washed 2 times with methanol and reuse reactions were performed. After 2 reuses a decrease on the conversion to $30 \%$ was observed (Figure 11). Previous works ${ }^{4,45}$ suggested that deactivation processes are likely related to $-\mathrm{SO}_{3} \mathrm{H}$ groups leaching and due to organic molecules, that poison the material active sites. Unlike other magnetic catalysts, which could be reused for 6 times, ${ }^{17,56}$ in this study the material did not present high stability, that could also be related to the synthesis method used.

In fact, leaching processes were also performed by leaving the catalyst in contact with methanol for $30 \mathrm{~min}$, after that, methanol was added to a flask with oleic acid. It can be seen that about $32 \%$ of the catalyst active sites were leached to the reaction medium.

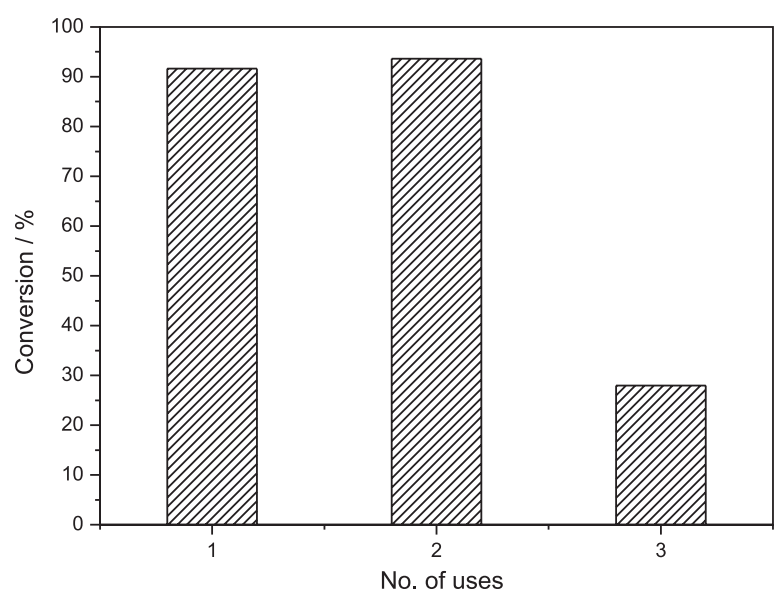

Figure 11. Oleic acid conversion versus number of uses on esterification reaction: recycling reactions of catalyst $(\mathrm{B} 8 \mathrm{Fe})_{450} \mathrm{~S}$. Reaction conditions: 10.0 wt. \% catalyst, $1: 30$ oleic acid:methanol, $100^{\circ} \mathrm{C}, 6 \mathrm{~h}$.

The catalytic tests showed that sulfonated materials were active to esterification reactions, with conversions of $90 \%$, however, the legislation requires a conversion of $>96 \%$. In that way, it would be necessary to increase the oleic acid:methanol ratio to move the reaction towards products formation or increase the number of acidic sites, adding more catalyst to the reaction medium.

The mechanism involves the proton of $\mathrm{SO}_{3} \mathrm{H}$ groups, which works as a Brønsted acid. Furthermore, at temperatures higher than $450{ }^{\circ} \mathrm{C}$, the materials were magnetic, which facilitates the material removal from reaction medium. Reuse tests of $(\mathrm{B} 8 \mathrm{Fe})_{450} \mathrm{~S}$ demonstrated that after 3 uses the conversion decreases to $30 \%$, probably because of leaching or methylation of $\mathrm{SO}_{3} \mathrm{H}$. Studies ${ }^{36}$ performed with a carbon based on bamboo catalyst showed that after $2 \mathrm{~h}$ of reaction, using $6 \mathrm{wt} . \%$ of catalyst, 1:5 oleic acid:ethanol at $90{ }^{\circ} \mathrm{C}$, the conversion was $97 \%$. However, after the $5^{\text {th }}$ use, the conversion decrease to $27.84 \%$.

The results obtained in this work, e.g., SEM, TEM, TG, Mössbauer and XRD, indicated that $\mathrm{Fe}^{3+}$ can be dispersed in bio-oil and upon thermal treatment at temperatures higher than $400{ }^{\circ} \mathrm{C}$ is reduced to form magnetite $\mathrm{Fe}_{3} \mathrm{O}_{4}$ nanoparticles:

$\mathrm{Fe}^{3+}{ }_{\text {bio-oil }} \rightarrow \mathrm{Fe}_{3} \mathrm{O}_{4} /$ carbon matrix

During decomposition the presence of oxidizing molecules, e.g., $\mathrm{H}_{2} \mathrm{O}$ and $\mathrm{CO}_{2}$, or when exposed to air, part of these $\mathrm{Fe}_{3} \mathrm{O}_{4}$ nanoparticles are oxidized to another magnetic phase maghemite $\gamma-\mathrm{Fe}_{2} \mathrm{O}_{3}$.

$\mathrm{Fe}_{3} \mathrm{O}_{4} /$ carbon matrix $\rightarrow \gamma-\mathrm{Fe}_{2} \mathrm{O}_{3} /$ carbon matrix

These materials can be sulfonated by a simple reaction with concentrated $\mathrm{H}_{2} \mathrm{SO}_{4}$. The most efficient sulfonation 


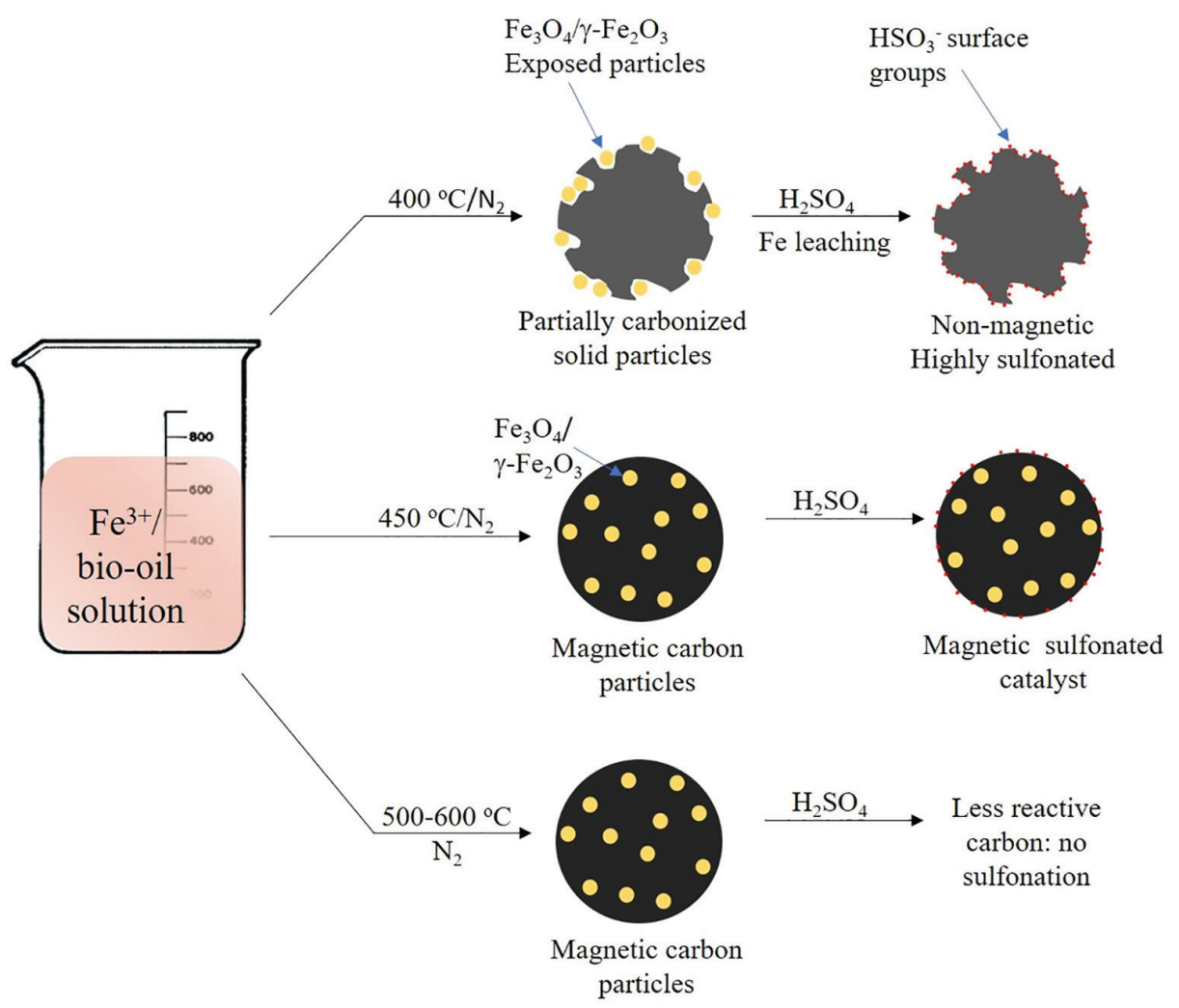

Figure 12. Scheme of carbonization and sulfonation processes of $\mathrm{Fe}^{3+} /$ bio-oil.

was observed for the material obtained at $400{ }^{\circ} \mathrm{C}$. However, sulfonation of the material $(\mathrm{B} 8 \mathrm{Fe})_{400}$ led to a strong $\mathrm{Fe}$ leaching indicating that the metal was exposed and not encapsulated by the carbon matrix. As a result of this leaching the material was not magnetic. On the other hand, the material obtained at $450{ }^{\circ} \mathrm{C},(\mathrm{B} 8 \mathrm{Fe})_{450}$, showed good results for the sulfonation process but no significant Fe leaching suggesting that the $\mathrm{Fe}$ oxide particles are protected/encapsulated in the carbon matrix. Thermal treatment at 500 and $600{ }^{\circ} \mathrm{C}$ produced carbons very resistant to sulfonation. These results are summarized schematically in Figure 12.

The material $(\mathrm{B} 8 \mathrm{Fe})_{450} \mathrm{~S}$ showed good results for the esterification of oleic acid reaching $90 \%$ of conversion, similar to the most efficient catalysts described in the literature,,$^{51}$ however, more studies should improve the material stability in the reaction medium.

\section{Conclusions}

The organic matrix bio-oil rich in oxygen functionalities can be used to efficiently dissolve/disperse $\mathrm{Fe}^{3+}$. Upon thermal treatment the bio-oil decomposition led to the formation of a carbonaceous matrix and the partial reduction of $\mathrm{Fe}^{3+}$ to $\mathrm{Fe}^{2+}$ to form magnetic nanoparticles of $\mathrm{Fe}_{3} \mathrm{O}_{4}$ and maghemite $\gamma-\mathrm{Fe}_{2} \mathrm{O}_{3}$. This composite based on $\mathrm{Fe}$ magnetic nanoparticles dispersed/encapsulated in a carbon matrix has several potential applications in adsorption, catalysis and materials science. The effect of pyrolysis temperature was important, once as temperature increases, the material becomes less reactive due to sulfuric acid. These magnetic carbons were used as acid catalyst in different reactions, such as esterification of oleic acid and methanol, which reached $90 \%$ of conversion. Reuse reactions were also performed and after $2^{\text {nd }}$ use, the conversion decreased to $30 \%$, being necessary other studies to improve the catalyst stability in reaction medium.

\section{Supplementary Information}

Supplementary data are available free of charge at http://jbcs.sbq.org.br as PDF file.

\section{Acknowledgments}

The authors acknowledge the UFMG microscopy center, INCT Midas, CNPQ, CAPES and FAPEMIG.

\section{Authors Contributions}

Fabiane C. Ballotin was responsible for the conceptualization, data curation, investigation, writing 
original draft, review and editing; Vitor F. Almeida for the data curation, investigation and validation; José D. Ardisson for the visualization, writing review and editing; Márcio J. da Silva for the visualization, writing original draft, review and editing; Ricardo R. Soares for the visualization, writing review and editing; Rochel M. Lago for the conceptualization, project administration, visualization, writing original draft, review and editing; Ana Paula C. Teixeira for the conceptualization, project administration, visualization, writing original draft, review and editing.

\section{References}

1. Mortensen, P. M.; Grunwaldt, J.-D.; Jensen, P. A.; Knudsen, K. G.; Jensen, A. D.; Appl. Catal., A 2011, 407, 1.

2. Bridgwater, A. V.; Biomass Bioenergy 2012, 38, 68.

3. Mullen, C. A.; Boateng, A. A.; Goldberg, N. M.; Lima, I. M.; Laird, D. A.; Hicks, K. B.; Biomass Bioenergy 2010, 34, 67.

4. Guo, X.; Zheng, Y.; Zhang, B.; Chen, J.; Biomass Bioenergy 2009, 33, 1469 .

5. Boateng, A.; Sadaka, S.; J. Anal. Appl. Pyrolysis 2012, 95, 38.

6. Kim, J.-S.; Bioresour. Technol. 2015, 178, 90.

7. Hew, K. L.; Tamidi, A. M.; Yusup, S.; Lee, K. T.; Ahmad, M. M.; Bioresour. Technol. 2010, 101, 8855.

8. Khromova, S. A.; Smirnov, A. A.; Selishcheva, S. A.; Kukushkin, R. G.; Dundich, V. O.; Trusov, L. I.; Yakovlev, V. A.; Catal. Ind. 2013, 5, 260.

9. Isa, K. M.; Ying, L. J.; Saad, S. S.; Kasim, F. H.; Rahim, M. A. A.; J. Adv. Res. Fluid Mech. Therm. Sci. 2016, 27, 12.

10. Yang, T.; Shi, L.; Li, R.; Li, B.; Kai, X.; Fuel Process. Technol. 2019, 184, 65.

11. Czernik, S.; French, R.; Feik, C.; Chornet, E.; Ind. Eng. Chem. Res. 2002, 41, 4209.

12. Oldham, D. J.; Fini, E. H.; Chailleux, E.; Constr. Build. Mater. 2015, 86, 75 .

13. Chaiwat, W.; Gunawan, R.; Gholizadeh, M.; Li, X.; Lievens, C.; Hu, X.; Wang, Y.; Mourant, D.; Rossiter, A.; Bromly, J.; Li, C.-Z.; Fuel 2013, 112, 302.

14. Mendonça, F. G.; Gomes, J. P. M.; Tristão, J. C.; Ardisson, J. D.; Soares, R. R.; Lago, R. M.; Fuel 2016, 184, 36.

15. Milina, M.; Mitchell, S.; Pérez-Ramírez, J.; Catal. Today 2014, 235, 176.

16. Ballotin, F. C.; Perdigão, L. T.; Rezende, M. V. B.; Pandey, S. D.; da Silva, M. J.; Soares, R. R.; Freitas, J. C. C.; Teixeira, A. P. C.; Lago, R. M.; New J. Chem. 2019, 43, 2430.

17. Li, X.; Shi, J.; Wang, Z.; Duan, X.; Chen, G.; Guan, Q.; Li, X.; Lei, T.; BioResources 2017, 12, 7525.

18. Pasinszki, T.; Krebsz, M.; Kótai, L.; Sajó, I. E.; Homonnay, Z.; Kuzmann, E.; Kiss, L. F.; Váczi, T.; Kovács, I.; J. Mater. Sci. 2015, 50, 7353 .
19. de Mendonça, F. G.; Rosmaninho, M. G.; da Fonseca, P. X.; Soares, R. R.; Ardisson, J. D.; Tristão, J. C.; Lago, R. M.; Environ. Sci. Pollut. Res. 2017, 24, 6151.

20. Tristão, J. C.; Oliveira, A. A. S.; Ardisson, J. D.; Dias, A.; Lago, R. M.; Mater. Res. Bull. 2011, 46, 748.

21. Al Faraj, A.; Shaik, A. P.; Shaik, A. S.; Int. J. Nanomed. 2014, $10,157$.

22. Dalal, M.; Greneche, J.-M.; Satpati, B.; Ghzaiel, T. B.; Mazaleyrat, F.; Ningthoujam, R. S.; Chakrabarti, P. K.; ACS Appl. Mater. Interfaces 2017, 9, 40831.

23. Yu, H.; Niu, S.; Lu, C.; Li, J.; Yang, Y.; Energy Convers. Manage. 2016, 126, 488.

24. Canivet, J.; Süss-Fink, G.; Green Chem. 2007, 4, 391.

25. Velasco, L. F.; Maurino, V.; Laurenti, E.; Fonseca, I. M.; Lima, J. C.; Ania, C. O.; Appl. Catal., A 2013, 452, 1.

26. Müller, F.; Ferreira, C. A.; Franco, L.; Puiggalí, J.; Alemán, C.; Armelin, E.; J. Phys. Chem. B 2012, 116, 11767.

27. Hasan, Z.; Hwang, J.-S.; Jhung, S. H.; Catal. Commun. 2012, 26, 30 .

28. Santos, E. M.; Teixeira, A. P. C.; da Silva, F. G.; Cibaka, T. E.; Araújo, M. H.; Oliveira, W. X. C.; Medeiros, F.; Brasil, A. N.; de Oliveira, L. S.; Lago, R. M.; Fuel 2015, 150, 408.

29. Liu, T.; Li, Z.; Li, W.; Shi, C.; Wang, Y.; Bioresour. Technol. 2013, 133, 618.

30. Dawodu, F. A.; Ayodele, O.; Xin, J.; Zhang, S.; Yan, D.; Appl. Energy 2014, 114, 819.

31. Mar, W. W.; Somsook, E.; Procedia Eng. 2012, 32, 212.

32. Brand, R. A.; Nucl. Instrum. Methods Phys. Res., Sect. B 1987, $28,398$.

33. Ngaosuwan, K.; Goodwin, J. G.; Prasertdham, P.; Renewable Energy 2016, 86, 262.

34. Li, H.; Wang, Y.; Zhu, Y.; Xu, X.; Wu, A.; Deng, X.; BioResources 2018, 13, 6221.

35. Chen, T.; Peng, L.; Yu, X.; He, L.; Fuel 2018, 219, 344.

36. Zhou, Y.; Niu, S.; Li, J.; Energy Convers. Manage. 2016, 114 , 188.

37. Ibrahim, N. A.; Rashid, U.; Taufiq-Yap, Y. H.; Yaw, T. C. S.; Ismail, I.; Energy Convers. Manage. 2019, 195, 480.

38. Zhang, H.; Luo, X.; Shi, K.; Wu, T.; He, F.; Yang, H.; Zhang, S.; Peng, C.; Carbon 2019, 147, 134.

39. Meshkani, F.; Rezaei, M.; Chem. Eng. Res. Des. 2015, 95 , 288.

40. Liu, W.-J.; Tian, K.; Jiang, H.; Yu, H.-Q.; Sci. Rep. 2013, 3, 2419.

41. Cuesta, A.; Dhamelincourt, P.; Laureyns, J.; Carbon 1994, 32, 1523.

42. Del Río, J. C.; Gutiérrez, A.; Romero, J.; Martínez, M. J.; Martínez, A. T.; J. Anal. Appl. Pyrolysis 2001, 58-59, 425.

43. Branca, C.; Giudicianni, P.; Di Blasi, C.; Ind. Eng. Chem. Res. 2003, 42, 3190.

44. Yu, H.; Niu, S.; Lu, C.; Li, J.; Yang, Y.; Fuel 2017, 208, 101. 
45. Wieczorek-Ciurowa, K.; Kozak, A. J.; J. Therm. Anal. Calorim. 1999, 58, 647.

46. Yu, M.; Zhong, C.; Zhang, Y.; Chen, Q.; Ao, X.; Lei, X.; Li, C.; J. Anal. Appl. Pyrolysis 2018, 134, 293.

47. Hara, M.; Yoshida, T.; Takagaki, A.; Takata, T.; Kondo, J. N.; Hayashi, S.; Domen, K.; Angew. Chem., Int. Ed. 2004, 43, 2955.

48. Kastner, J. R.; Miller, J.; Geller, D. P.; Locklin, J.; Keith, L. H.; Johnson, T.; Catal. Today 2012, 190, 122.

49. Takagaki, A.; Toda, M.; Okamura, M.; Kondo, J. N.; Hayashi, S.; Domen, K.; Hara, M.; Catal. Today 2006, 116, 157.

50. Lou, W.-Y.; Zong, M.-H.; Duan, Z.-Q.; Bioresour. Technol. 2008, 99, 8752 .

51. Araujo, R. O.; Chaar, J. S.; Queiroz, L. S.; da Rocha Filho, G. N.; da Costa, C.; da Silva, E. F.; Landers, G. C. T.; Costa, R.;
Costa, M. J. F.; Gonçalves, A. A. S.; de Souza, L. K. C.; Energy Convers. Manage. 2019, 196, 821.

52. Neeli, S. T.; Ramsurn, H.; Carbon 2018, 134, 480.

53. Kumar, U.; Maroufi, S.; Rajarao, R.; Mayyas, M.; Mansuri, I.; Joshi, R. K.; Sahajwalla, V.; J. Cleaner Prod. 2017, 158, 218.

54. Fraga, A. C.; Quitete, C. P. B.; Ximenes, V. L.; Sousa-Aguiar, E. F.; Fonseca, I. M.; Rego, A. M. B.; J. Mol. Catal. A: Chem. 2016, 422, 248.

55. Saravanan, K.; Tyagi, B.; Shukla, R. S.; Bajaj, H. C.; Appl. Catal., B 2015, 172-173, 108.

56. Li, J.; Liang, X.; Energy Convers. Manage. 2017, 141, 126.

Submitted: January 22, 2020

Published online: March 30, 2020 